\title{
REVISITING THE MORPHOPHONOLOGY OF THANGMI: A TIBETO-BURMAN LANGUAGE OF NEPAL
}

\begin{abstract}
Mark Turin
This article revisits the morphophonology of Thangmi, a Tibeto-Burman language spoken in Nepal by a community group of the same name whose grammar and lexicon I was involved in documenting from 1996 onwards. The Thangmi (Nepali Thāmī) are an ethnic group who number around 30,000 and inhabit the central eastern hills of Nepal. The Thangmi are autochthonous to the upper reaches of Dolakhā district as well as to the eastern valleys of Sindhupālcok district, and their hitherto undocumented Tibeto-Burman language has two distinctly recognisable and mutually unintelligible dialects.Morphophonology (also known as morphophonemics) explores the interaction between morphology and phonology, and is predicated on a rigorous investigation of the phonological variations within morphemes that oftentimes mark different grammatical functions. While complex, Thangmi morphophonology lends itself to transparent interpretation, and this paper offers a modified analysis that builds on and develops from my earlier work (Turin 2012, 2005). Following a brief introduction to Thangmi segmental phonology, this article covers four aspects central to Thangmi morphophonology: the remnants of what may be a defunct liquid-nasal alternation, a brief overview of assimilation, a robust review of intervocalic approximants and finally a brief note on syncope.
\end{abstract}

Keywords: Thami, Thangmi, Morphophonology, Assimilation, Syncope

\section{The Thangmi speech community}

The Thangmi are autochthonous to the upper reaches of Dolakhā district as well as to the eastern valleys of Sindhupālcok district, and their hitherto undocumented Tibeto-Burman language has two distinctly recognisable and mutually unintelligible dialects. ${ }^{1}$ The greatest concentration of ethnic Thangmi and speakers of the language are resident in these two districts.

According to the 2011 National Population and Housing Census conducted by the Central Bureau of Statistics, the total Thami population is 28,671 (2012: 145), 90\% of whom are classified as rural and resident in the Central Development Region. The same census enumerates 23,151 Thangmi 'mother tongue' speakers (2012: 164), which-given that there are next to no speakers of Thangmi who are not members of the Thami ethnic communities - entails that $80 \%$ of the population self-identify as speakers of their ancestral language.

The Thangmi language likely occupies a genetic position somewhere between the Kiranti or 'Rai' group of languages spoken in the east of Nepal, and the Newar language as spo-

\footnotetext{
${ }^{1}$ I am grateful to the editorial team of this journal, in particular Dubi Nanda Dhakal, Lekhnath Sharma Pathak and Bhim Narayan Regmi, for their support and encouragement, and to the reviewer who offered constructive and welcome suggestions to improve this contribution. This article was written on the traditional, ancestral

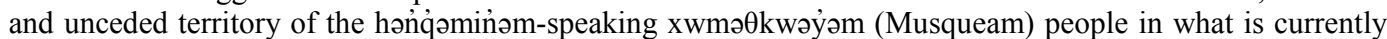
referred to as Vancouver, British Columbia, Canada. I thank the Musqueam community for their teachings.
}

Gipan 4. 2019. 63-79. 
64 / Revisiting the morphophonology of...

ken in Dolakhā and around the Kathmandu valley. The Thangmi language exhibits certain grammatical features reminiscent of the Kiranti languages, but has a lexicon more closely allied to Newar, and perhaps Barām. The exact genetic position of the Thangmi language in the Tibeto-Burman language family remains contested and is firmly beyond the scope of this paper. Instead, I refer interested readers to other contributions that address this important question (cf. Turin 2004 1998).

Since the mid-1990s, and perhaps earlier, members of the Thangmi speech community have been actively engaged in collaborative processes of language and culture collection, documentation, description, conservation and increasingly revitalization. In some instances, these initiatives have articulated with national research and advocacy programs in $\mathrm{Ne}$ pal, or with movements for state recognition in West Bengal in neighbouring India, as well as with the research agendas of foreign linguists and anthropologists.

2. The importance of morphophonology for grammatical description

Morphophonology is the branch of linguistics that deals with the phonological representation of morphemes. As noted by Basbøll (2015), morphophonology should not be understood as a distinct subfield or element of linguistics, but rather as an exploration of the composite elements of morphology and phonology. While in this article we choose to use the term morphophonology, we acknowledge that the Americanist tradition has - at least since Bloomfield's seminal study of Menomini-historically favoured the term morphophonemics over morphophonology, perhaps suggesting more of an "emphasis on the segmental building blocks in linguistic structure than the other terms which are neutral with respect to the distinction between segments and prosody" (Basbøll 2015: 826).

The centrality of morphophonology can best be explained thus: while phonetic and phonemic transcriptions rely exclusively on input from sound, morphophonemic transcriptions by contrast also involve morphological information (Basbøll 2015: 831). Heuristically, then, "two phonemes can be identified morphophonemically if they occur in parallel positions in different forms of the same morpheme-e.g. in different inflectional forms belonging to the same paradigm - if it applies to a significant set of morphemes in a systematical way" (Basbøll 2015: 831). This last point is central for morphophonological analysis: variations and alternations must be at once significant and systematic. When well-handled and carefully described, a morphophonemic analysis will help to make "phonological patterns simpler and more general, e.g., with simpler phonotactics and more general principles of realization" (Basbøll 2015: 831). It is such a handling that we strive for in this contribution.

\section{A brief overview of Thangmi phonology}

Thangmi distinguishes six monophthongal vowels /i/, /u/, /e/, /o/, /a/, /ă/ representing three grades of vowel height and three steps on the front-back scale. Thangmi exhibits no contrast between short and long vowels, but does distinguish seven diphthongs /ei/, /ăi/, /oi/, /ui/, /eu/, /ău/, /ou/. 
Although Thangmi boasts more vowel diphthongs than monophthongs, diphthongs occur only infrequently in native Thangmi words. While it may seem peculiar to suggest that Thangmi has more diphthong than monophthong vowels, this proposition is the result of careful examination. A Thangmi diphthong is indeed the union of two vowels pronounced as one syllable, and may not be analysed as a sequence of two monophthongs. Diphthongs are more common, however, in open-stem verbs borrowed from Nepali, as in Thangmi ghumăisa 'to turn around, show around' from Nepali ghumāunu 'to turn around, show around', and Thangmi banăisa 'to make' from Nepali banāunu 'to make'. Diphthongs are attested in a handful of indigenous Thangmi forms, in which they have the same length as a monophthongal vowel. The criterion of length provides the justification for analysing these vowel forms as diphthongs rather than as vowel sequences or chains.

The Thangmi consonant inventory is comprised of five series of obstruents across five distinctive and contrastive points of articulation (bilabial, dental, palatal, retroflex and velar), each of which includes an unaspirated voiceless, an aspirated voiceless, an unaspirated voiced and a breathy member. The Thangmi consonant system further includes a series of nasals at four points of articulation, one breathy nasal, one glottal stop, one fricative, one trill, one lateral and three approximants. Apart from the glottal stop / $/$, all consonants may occur in word-initial position.

Stress is non-distinctive, prosodic and relatively unpronounced in Thangmi. Unless otherwise indicated, all Thangmi words are stressed on the first syllable. The only deviations from this rule are Thangmi verb forms composed of three syllables of more, in which the stress falls on the second syllable. Thangmi does not permit sequences of consonants in syllable-final position. In syllable-initial position, the only consonant clusters attested are those in which the second phoneme is either $/ 1 /, / \mathrm{r} /, / \mathrm{y} /$ or $/ \mathrm{w} /$. These four consonant phonemes then function as post-consonantal glides. At syllable breaks in Thangmi words, consonant clusters are attested in so far as they involve the closed coda of one syllable and a consonant initial in the following segment.

Gemination is the adjacent clustering of identical consonants within a phonological word. The phonetic value of geminate consonants is discerned to be different to single consonants on the basis of clearly audible length. The consonants $/ \mathrm{p} /, / \mathrm{t} /, / \mathrm{t} /, / \mathrm{k} /, / \mathrm{n} /, / \mathrm{f} /, / \mathrm{s} /$ and $/ 1 /$ are attested as geminates in native Thangmi lexical items.

Certain Thangmi vowels are lengthened for emphasis or as the result of bearing the prosodic accent of a clause or sentence. These lengthened vowels occur primarily in adjectives, adverbs and interjections when the speaker intends to convey an intensified feeling or emotion. Examples include ho to (yes that) 'yes, that one' from Nepali ho 'yes' and Thangmi to 'he, she, it (distal)' which is rendered as [ho: to:] and atthe apraca 'very good, excellent' which is often pronounced with lengthened initial vowels on each word, as in [a:tt $\varepsilon$ a:pratsa]. When giving directions, older Thangmi speakers use vowel lengthening to indicate relative distance and the difficulty of the terrain, as in dhu-te hen-ko 
66 / Revisiting the morphophonology of...

$m a ̆ i-\varnothing-d u$ (over.there-LOC go-ADH must-SAS-NPT) 'you must go over there', in which [d $\mathrm{d}^{\mathrm{h}} \mathrm{u}$ ] is often rendered as $\left[\mathrm{d}_{n}^{\mathrm{h}} \mathrm{u}:\right]$ to underscore the distance.

4. Thangmi morphophonology

The morphophonological regularities which are attested in the Thangmi language, or within a defined grammatical category, are the topic of this short contribition. In line with estalished convention, morphemes and allomorphs are represented between mopheme brackets, as in <-si $>$ (REF). Such a form is considered to be the underlying representation which may then undergo environmentally condtioned modifications. A phonetic form is represented in square brackets, as in [si], and a phonologically correct representation is italicised with no brackets, as in si.

\section{Remnants of a liquid-nasal alternation}

Thangmi displays the remnants of what may be a defunct liquid-nasal alternation. Unlike Korean (Suen n.d.), Lai (Melnik 1997) and Yamphu, the latter which still attests an alternation of liquid initials in suffixes and auxiliary verbs (Rutgers 1998: 40), Thangmi retains a mere handful of examples of a system which may once have been more productive. The four instances of liquid-nasal variation attested in modern spoken Thangmi show an alternation between the voiced, apico-alveolar approximant /1/ [1] and the voiced, retroflex nasal continuant /n/ [n], as shown below:

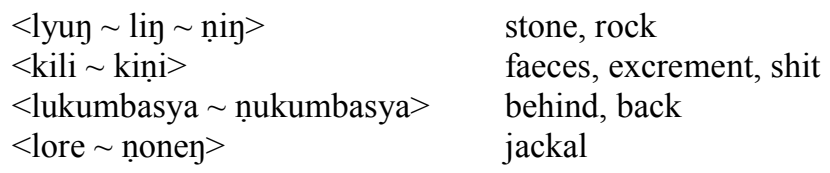

While the alternation of $/ 1 /$ and $/ \mathrm{n} /$ is most commonly heard in the forms shown above, older monolingual Thangmi speakers use $/ 1 /$ and $/ \mathrm{n} /$ interchangeably in scores of native Thangmi words. In particular, popular alternations include $<l u \sim$ ṇu $>$ 'later, after' and $<$ lumsa $\sim$ ṇumsa $>$ 'to sink into water' (both Sindhupālcok dialect). These alternates are rejected by younger speakers.

\section{Assimilation}

Assimilation is a common phonological process in all languages by which one sound becomes more like a nearby sound in its immediate environment. Assimilation can occur either within a word or between words, and while it occurs in normal speech, in most languages it becomes more common and pronounced in more rapid speech. Jurgec (2011: 12) defines assimilation as "an alternation involving at least two segments. One of these segments (the target) alternates in the presence of the other segment (the trigger), but not otherwise. The target acquires a phonological property of the trigger".

In Thangmi, verb stems and nouns that end in a voiced, velar nasal [y] are morphophonologically 'weak'. This weakness entails that under certain conditions, the segment does not retain its regular phonological identity but assimilates to the segments 
that follow, bringing about a regular alternation in the verb stem or nominal final. Before a short, mid-open, unrounded front vowel /e/ [c], a voiced, velar nasal final is subject to regressive assimilation for place of articulation. The result is a palatalised /ny/ [n], as in the following five examples:

wany-ey-du they're coming up from below

[wankndu]

$<$ wan-en-du>

come.from.below-pAS-NPT

dany-ey-no they sought

[danknno]

$<$ dan-en-no $>$

seek-pAS-3 $\rightarrow 3 /$ PT

lony-ey-ya-n they did [it] to me

[lonenyan]

$<$ lon-en-na-n $>$

do-pAS-1s-PT

nany-eyou (singular) (ERG)

[yane]

$<$ nan-e $>$

you(s)-ERG

su-bany-e who (plural) (ERG)

[subane]

$<$ su-ban-e $>$

who-Pp-ERG

This assimilation is represented by the following rule:

$\sum / \mathrm{y} / \rightarrow \sum / \mathrm{ny} / \quad / \quad / \mathrm{e} /$

7. The morphophonology of intervocalic approximants

When followed by a vowel-initial verbal agreement suffix, Thangmi open-stem verbs are realised with an intervocalic glide, either $/ \mathrm{h} /, / \mathrm{y} /$ or $/ \mathrm{w} /$, an example of which is amiy- $\varnothing$ an (sleep-SAS-3S/PT) 'he/she/it slept', from ami-sa 'to sleep'. The rules governing each vowel cluster combination are presented alongside illustrative examples below. The rule governing a vowel-initial verbal agreement suffix following an open-stem verb ending with a short, open, unrounded, front vowel [a] is as follows:

$\sum / \mathrm{a} / \rightarrow\left\{\begin{array}{ll}\sum / \mathrm{ah} / & {\left[\begin{array}{l}-\mathrm{a} / \\ / \mathrm{o} / \\ / \mathrm{u} /\end{array}\right]} \\ \sum / \mathrm{ay} / & {\left[\begin{array}{l}/ \mathrm{e} / \\ -\mathrm{i} /\end{array}\right]}\end{array}\right]$ 
68 / Revisiting the morphophonology of...

For the rule

$\sum / \mathrm{a} / \sum / \mathrm{ah} / \quad / \quad / \mathrm{a} /$

examples include:

thah-an he/she/it became

[thafian]

$<$ tha- $\varnothing$-an>

be-sAS-3S/PT

cawah-an he/she/it walked

[tsawahan]

$<$ cawa-Ø-an>

walk-sAS-3S/PT

For the rule

$\sum / \mathrm{a} / \mathrm{L} / \mathrm{ah} / \quad / \quad$ /o/

examples include:

yah-o! say it!

[yaho]

$<$ ya-o $>$

say-s $\rightarrow 3 /$ IMP

tortah-o! leave it!

[tortafio]

$<$ torta-o >

leave-s $\rightarrow 3 /$ IMP

For the rule

$\sum / \mathrm{a} / \sum / \mathrm{ah} / \quad / \mathrm{d} /$

examples include:

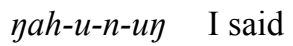

[yahunun]

$<$ ya-u-n-uy $>$

say-3P-1s $\rightarrow 3-1 \mathrm{~s} \rightarrow 3 / \mathrm{PT}$

cyah-u-no he/she/it ate

[tsjahuno]

$<$ cya-Ø-u-no>

eat-sAS-3P-3 $\rightarrow 3 / \mathrm{PT}$

For the rule

$\sum / \mathrm{a} / \rightarrow \sum$ /ay/ $/$ /e/ 
examples include:

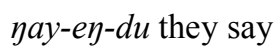

[yajendu]

$<$ ya-ey-du>

say-pAS-NPT

usyay-ey-an he/she/it danced

[usjajenan]

$<$ usya-en-an>

dance-pAS-3S/PT

For the rule

$\sum / \mathrm{a} / \sum_{\mathrm{a}} / \mathrm{ay} / \quad / \mathrm{i} /$

examples include:

ray-i- $n$ we came

[rajın]

$<$ ra-i-n $>$

come.from.level-1pPS-PT

thay- $i-d u$ we are

[ $\mathrm{t}^{\mathrm{h}}$ ajidu]

$<$ tha-i-du>

be-1pPS-NPT

The rule governing a vowel-initial verbal agreement suffix following an open-stem verb ending with a short, mid-open, unrounded front vowel $[\varepsilon]$ is as follows:

$$
\sum / \mathrm{e} / \rightarrow\left\{\begin{array}{ll}
\sum / \mathrm{ey} / & {\left[\begin{array}{l}
{[/ \mathrm{a} /} \\
/ \mathrm{e} / \\
/ \mathrm{i} /
\end{array}\right]} \\
\sum / \mathrm{eh} / & {\left[\_/ \mathrm{u} /\right]} \\
\sum / \mathrm{ew} / & {\left[\_/ \mathrm{o} /\right]}
\end{array}\right]
$$

For the rule

$\sum / \mathrm{e} / \mathrm{i} / \mathrm{ey} / \quad / \quad$ /a/

an example is:

ikhey-an it crowed

[ik ${ }^{\mathrm{h}}$ cjan]

$<$ ikhe- $\varnothing$-an $>$

crow-SAS-3S/PT 
70 / Revisiting the morphophonology of...

For the rule

$\sum / \mathrm{e} / \sum / \mathrm{ey} / \mathrm{l}$ /e/

an example is:

ney-ey-to-le having ground

[ncjentole]

$<$ ne-en-to-le>

grind-pAS-TPP-PCL

For the rule

$\sum / \mathrm{e} / \sum$ ley/ / _ /i/

an example is:

$n e y-i-n y o u / h e /$ they beat us

[ncjin]

$<$ ne-i-n>

beat-1pPS-PT

For the rule

$\sum / \mathrm{e} / \sum / \mathrm{eh} / \quad / \mathrm{lu} /$

an example is:

koteh-u-du he/she/it cuts

[kotchudu]

<kote-Ø-u-du>

cut-sAS-3P-NPT

For the rule

$\sum / \mathrm{e} / \mathrm{L} / \mathrm{ew} / \quad / \quad$ /o/

an example is:

sew-o! taste it!

[sewo]

$<$ se-o>

taste-s $\rightarrow 3 /$ IMP

The rule governing a vowel-initial verbal agreement suffix following an open-stem verb ending with a short, unrounded, high front vowel [i] is shown below:

$\sum / \mathrm{i} / \rightarrow\left\{\begin{array}{ll}\sum / \mathrm{iy} / & {\left[\begin{array}{c}{[/ \mathrm{a} /} \\ -/ \mathrm{e} / \\ -\mathrm{i} / \\ -/ \mathrm{o} /\end{array}\right]} \\ \sum / \mathrm{ih} / \sim / \mathrm{iy} / & {\left[\_/ \mathrm{u} / \mathrm{J}\right.}\end{array}\right]$ 
For the rule

$\sum / \mathrm{i} / \rightarrow \sum / \mathrm{iy} / \quad /$ /a/

an example is:

amiy-an he/she/it slept

[amijan]

$<$ ami-Ø-an>

sleep-sAS-3S/PT

For the rule

$\sum / \mathrm{i} / \rightarrow \sum / \mathrm{iy} / \quad /$ /e/

an example is:

piy-en-no they gave

[pijenno]

$<$ pi-en-no $>$

give-pAS- $3 \rightarrow 3 / \mathrm{PT}$

For the rule

$\sum / \mathrm{i} / \rightarrow \sum / \mathrm{iy} / \quad /$ _i $/$

an example is:

ariy- $i-n \quad$ we were afraid

[arijin]

$<$ ari-i-n>

be.afraid-1pPS-PT

For the rule

$\sum / \mathrm{i} / \rightarrow \sum / \mathrm{iy} / \quad /$ /o/

an example is:

ciy-o! throw it away!

[tsijo]

$<$ ci-o>

throw.away-s $\rightarrow 3 /$ IMP

For the following rule, the glides /ih/ and /iy/ exist in free variation, and are both equally attested in open-stem verb forms in allegro Thangmi speech.

For the rule

$\sum / \mathrm{i} / \quad \sum$ ih $\sim \mathrm{iy} / \quad / \quad \ldots$ u/ 
72 / Revisiting the morphophonology of...

Examples include:

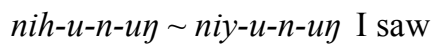

[nifunuy $\sim$ nijunuy]

$<$ ni-u-n-un>

see-3P- $1 \mathrm{~S} \rightarrow 3-1 \mathrm{~s} \rightarrow 3 / \mathrm{PT}$

pih-Ø-u-no $\sim$ piy-Ø-u-no he/she/it gave

[pifiuno $\sim$ pijuno]

$<$ pi-Ø-u-no $>$

give-sAS-3P-3 $\rightarrow 3 / \mathrm{PT}$

The rule governing a vowel-initial verbal agreement suffix following an open-stem verb ending with a short, mid-closed, rounded, back vowel [o] is shown below:

$\sum / \mathrm{o} / \rightarrow\left\{\begin{array}{ll}\sum / \mathrm{oy} / & {\left[\begin{array}{l}{[/ \mathrm{e} /} \\ -\mathrm{i} /\end{array}\right]} \\ \sum / \mathrm{oh} / & {\left[\begin{array}{l}{[/ \mathrm{o} /} \\ -\mathrm{u} /\end{array}\right]} \\ \sum / \mathrm{ow} / & {\left[\_/ \mathrm{a} /\right]}\end{array}\right]$

For the rule

$\sum / \mathrm{o} / \sum$ /oy/ $/$ /e/

an example is:

yoy-ey-no they looked at [something]

[jojeyno]

<yo-en-no>

look.at-pAS-3 $\rightarrow 3 / \mathrm{PT}$

For the rule

$\sum / \mathrm{o} / \sum$ /oy/ / _ / $/$

an example is:

poy-i-n you/he/they chased us

[pojin]

$<$ po-i-n>

chase-1pPS-PT

For the rule

$\sum / \mathrm{o} / \sum / \mathrm{oh} / \quad / \mathrm{lo} /$ 
an example is:

toh-o! dig!

[toho]

$<$ to-o $>$

dig-s $\square 3 /$ IMP

For the rule

$\sum / \mathrm{o} / \sum / \mathrm{oh} / \mathrm{L} / \mathrm{u} /$

an example is:

$y o h-u-d u$ he/she/it looks at [something]

[johudu]

$<$ yo-Ø-u-du>

look.at-sAS-3P-NPT

For the rule

$\sum / \mathrm{o} / \mathrm{L}_{\mathrm{L}} / \mathrm{ow} / \mathrm{L} / \mathrm{a} /$

an example is:

mow-an he/she/it survived

[mowan]

$<$ mo-Ø-an>

survive-sAS-3S/PT

The rule governing a vowel-initial verbal agreement suffix following an open-stem verb ending with a short, closed, rounded high back vowel [u] is shown below:

$\sum / \mathrm{u} / \rightarrow\left\{\begin{array}{ll}\sum / \mathrm{uy} / & {\left[\begin{array}{l}-\mathrm{e} / \\ -\mathrm{i} /\end{array}\right]} \\ \sum / \mathrm{uw} / & {\left[\begin{array}{l}-\mathrm{a} / \\ -/ \mathrm{o} /\end{array}\right]} \\ \sum / \mathrm{uh} / & {\left[\_/ \mathrm{u} /\right]}\end{array}\right]$

For the rule

$\sum / \mathrm{u} / \sum / \mathrm{uy} / \quad / \quad / \mathrm{e} /$

an example is:

cabuy-ey-du they carry

[tsabujendu]

$<$ cabu-en-du>

carry-pAS-NPT

For the rule

$\sum / \mathrm{u} / \rightarrow \sum / \mathrm{uy} / \quad / \quad$ /i/ 
74 / Revisiting the morphophonology of...

an example is:

nuy-i-n we laughed

[nujin]

$<$ nu-i-n $>$

laugh-1pPS-PT

For the rule

$\sum / \mathrm{u} / \quad \rightarrow$ Lww $/$ / $/$

an example is:

yuw-an he/she/it came from above

[juwan]

$<$ ju-Ø-an>

come.from.above-sAS-3S/PT

For the rule

$\sum / \mathrm{u} / \sum / \mathrm{uw} / \quad / \quad$ /o/

an example is:

chyuw-o! tie it up!

[ts ${ }^{\mathrm{h}}$ juwo]

$<$ chyu-o $>$

tie-s $\rightarrow 3 /$ IMP

For the rule

$\sum / \mathrm{u} / \sum / \mathrm{uh} / \quad / \quad / \mathrm{u} /$

an example is:

dapuh- $u$ - $d u$ he/she/it spies

[dapufudu]

$<$ dapu- $\emptyset$-u-du>

spy-sAS-3P-NPT

Verb stems ending in a diphthong also take an intervocalic glide when followed by a vowel-initial verbal agreement suffix. The examples provided are represented by the rules below. The rule governing a vowel-initial verbal agreement suffix following an openstem verb ending with the diphthong /ăi/ is as follows:

$\sum /$ ăi $\rightarrow\left\{\sum /\right.$ ăiy/ $\left.\left[\begin{array}{l}-/ \mathrm{a} / \\ -/ \mathrm{e} / \\ -/ \mathrm{i} / \\ -/ \mathrm{d} / \\ -/ \mathrm{u} /\end{array}\right]\right\}$ 
Examples include:

măiy-an he/she/it must [preterite tense]

[maijan]

$<$ măi-Ø-an>

must-sAS-3S/PT

săiy-en-nothey knew

[saijenno]

$<$ săi-en-no $>$

know-pAS-3 $\rightarrow 3 / \mathrm{PT}$

karăiy-i- $n$ we feel [hungry]

[karaijin]

$<$ karăi-i-n>

shout-1pPS-PT

nasăiy-o! listen!

[nasarjo]

$<$ nasăi-o $>$

hear-s $\rightarrow 3 /$ IMP

kăiy-u-du he/she/it removes

[kaijudu]

$<$ kăi-Ø-u-du>

remove-sAS-3P-NPT

The rule governing a vowel-initial verbal agreement suffix following an open-stem verb ending with the diphthong /ei/ is as follows:

$\sum / \mathrm{ei} / \quad \sum / \mathrm{eiy} / \quad\left\{\begin{array}{c}/ \mathrm{a} / \\ -/ \mathrm{u} /\end{array}\right\}$

Examples include:

kheiy-an it spilled

$\left[\mathrm{k}^{\mathrm{h}} \varepsilon \mathrm{jjan}\right]$

$<$ khei-Ø-an>

spill-sAS-3S/PT

kheiy-u-no he/she/it poured

[ $\left.\mathrm{k}^{\mathrm{h}} \varepsilon \mathrm{ijuno}\right]$

$<$ khei- $\varnothing$-u-no $>$

pour-sAS-3P-3 $\rightarrow 3 /$ PT

The rule governing a vowel-initial verbal agreement suffix following an open-stem verb ending with the diphthong /ui/ is as follows:

$\sum /$ ui/ $\rightarrow \sum$ /uiy/ / _/a/ 
76 / Revisiting the morphophonology of...

an example of which is:

nuiy-an he/she/it laughed

[nujan]

$<$ nui- $\varnothing$-an>

laugh-SAS-3S/PT

The rule governing a vowel-initial verbal agreement suffix following an open-stem verb ending with the diphthong /ou/ is as follows:

$\sum / \mathrm{ou} / \rightarrow\left\{\begin{array}{ll}\sum / \text { ouw/ } & {\left[{ }_{1} / \mathrm{a} /\right\}} \\ \sum / \text { ouy/ } & {\left[{ }_{-} / \mathrm{i} /\right\}} \\ \sum / \mathrm{ouh} / & {\left[{ }_{-} / \mathrm{u} /\right\}}\end{array}\right]$

Examples include:

aghyouw-an he/she/it cried out

[aghjouwan]

$<$ aghyou- $\varnothing$-an $>$

cry.out-sAS-3S/PT

urouy-i-n you/he/they called us

[uroujin]

$<$ urou-i-n>

call-1pPS-PT

urouh-u-du he/she/it calls

[uroufudu]

$<$ urou- $\varnothing-\mathrm{u}-\mathrm{du}>$

call-sAS-3P-NPT

Younger Thangmi speakers of the Dolakhā dialect with increasing fluency in Nepali sometimes disregard the morphophonology of open verb stems when the initial of the following verbal agreement suffix is the same vowel as the verb stem. In such cases, younger speakers may lengthen the vowel of the verb stem, as shown in the examples below:

tha-an he/she/it became

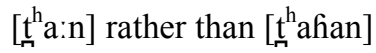

$<$ tha- $\varnothing$-an>

be-SAS-3S/PT

ne-ey-to-le having ground

[ne:ntole] rather than [ncjentole]

$<$ ne-en-to-le>

grind-pAS-TPP-PCL 


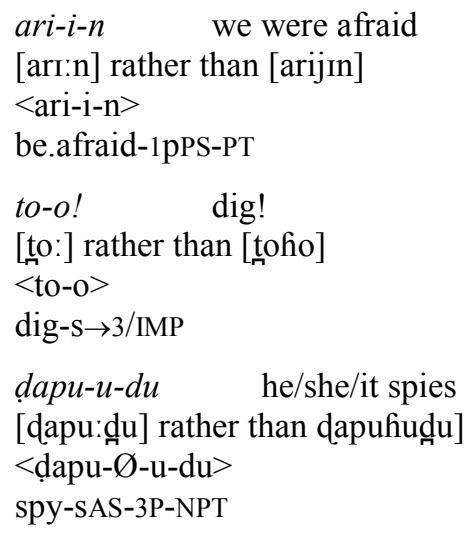

Thangmi speakers from the village of Piskar in Sindhupālcok district insert a glottal stop in the place of a glide. This intervocalic hiatus prevents diphthongisation. The phenomenon of a hiatus is not attested elsewhere in Sindhupālcok, and is also rejected by speakers of the Dolakhā dialect of Thangmi. The following three examples demonstrate this glottalisation:

tha?-an he/she/it became

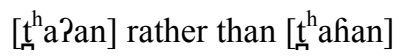

$<$ tha- $\varnothing$-an $>$

be-sAS-3S/PT

to?-o! dig!

[to?o] rather than [tofio]

$<$ to-o $>$

dig-S $\rightarrow 3 /$ IMP

yu?-an he/she/it came from above

[juPan] rather than [juwan]

$<$ ju-Ø-an>

come.from.above-sAS-3S/PT

\section{Syncope}

Syncope is the loss of one or more sounds from the interior of a word, especially the loss of an unstressed vowel. In Thangmi, this internal omission of sounds in is manifested in vowel syncope, and is a defining feature of both the Dolakhā and Sindhupālcok dialects when a verb stem has the following structure:

$\mathrm{C} \mathrm{V} / \mathrm{r} / \mathrm{V}$ 
78 / Revisiting the morphophonology of...

In such instances, as shown in the examples below, the first vowel may be syncopated. While both vowel syncope and vowel retention are attested, the rate of omission increases with connected or flowing natural speech: ${ }^{2}$

dorok-an $\sim$ drok-an he/she/it ran

[dorokan $\sim$ drokan]

$<$ dorok- $\varnothing$-an>

run-sAS-3S/PT

serek-an $\sim$ srek-an he/she/it got up

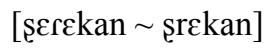

$<$ serek- $\varnothing$-an>

arise-SAS-3S/PT

9. Conclusion

While complex, Thangmi morphophonology lends itself to transparent interpretation and analysis. Following a brief introduction to Thangmi segmental phonology, this article has outlined four aspects central to Thangmi morphophonology: the remnants of what may be a defunct liquid-nasal alternation, a brief overview of assimilation, a robust review of intervocalic approximants and finally a brief note on syncope. Once again, while the linguistic and cultural affinities between Thangmi and the Rai-Kiranti groupings of languages in eastern Nepal and the Newar language as spoken in Dolakha and the Kathmandu valley are certainly worthy of additional exploration, these questions are beyond the remit of this paper and will not be answered by a synchronic and language-internal analysis of morphophonology.

Abbreviations

A agent (of a transitive verb)

$\mathrm{ADH}$ adhortative

CLF non-human numeral classifier

DIM diminutive

FEM feminine, female gender

(G) glide

IMP imperative

INF infinitive

IPP intr. preterite participle

MALEmasculine, male gender

NPS neg. participial suffix

OPT optative

$\mathrm{P} \quad$ patient (of a transitive verb)

PERM permissive

PM patient marker

PRT particle

\begin{tabular}{|c|c|}
\hline $\begin{array}{l}\text { ABL } \\
\text { CAU }\end{array}$ & causative \\
\hline $\mathrm{CON}$ & continuous background activity suffix \\
\hline ERG & ergative \\
\hline FOC & focus particle \\
\hline GEN & genitive \\
\hline IND & individuative suffix \\
\hline INS & instrumental \\
\hline LOC & locative \\
\hline NEG & negative \\
\hline NPT & non-preterite \\
\hline $\mathrm{p}$ & plural \\
\hline PCL & participial \\
\hline PFG & perfect gerund \\
\hline $\mathrm{Pp}$ & pronominal plural \\
\hline PSG & present gerund \\
\hline
\end{tabular}

${ }^{2}$ The same is true in English, in which certain cases of syncope are conventions which speed up or simplify speech patterns, as in ['sckritri] rather than ['sekriteri] 'secretary'. 
PT preterite

REP reported speech particle

$\mathrm{S}$ subject

vs versus

[...] phonetic transcription

$<\ldots>$ morpheme/allomorph

$\rightarrow \quad$ direction of a transitive relationship

1 first person

3 third person
REF reflexive

S singular

TPP transitive preterite participle

$\varnothing \quad$ zero-marker

/.../ phonemic transcription

$<\quad$ derives from

$\sim \quad$ alternates with

2 second person

$\sum$ stem

References

Basbøll, Hans. 2015. Morphophonology. International Encyclopedia of the Social \& Behavioral Sciences ( $2^{\text {nd }}$ edn.) Volume 15. 826-833.

Bloomfield, Leonard. 1939. Menomini morphophonemics. Travaux du Cercle Linguistique de Prague 8. 105-115.

Central Bureau of Statistics. 2012. National Population and Housing Census 2011. Kathmandu: National Planning Commission Secretariat.

Melnik, Nurit. 1997. Verbal alternations in Lai. Linguistics of the Tibeto-Burman Area 20(2). 163172.

Rutgers, Roland. 1998. Yamphu: Grammar, Texts and Lexicon. Leiden: Research School CNWS.

Suen, Yeuk Hay Carmen. n.d. Alternation of /n/ and /1/ in Korean Language. Unpublished paper. City University of Hong Kong: Department of Chinese, Translation and Linguistics.

Turin, Mark. 2012. Grammar of Thangmi with an Ethnolinguistic Introduction to the Speakers and their Culture. Brill's Tibetan Studies Library, Languages of the Greater Himalayan Region, 5/6. Leiden: Brill.

Turin, Mark. 2005. The Morphophonology of Thangmi: A Tibeto-Burman Language of Nepal. In Yadava, Y. P., G. R. Bhattarai, R. R. Lohani, B. Prasain and K. Parajuli (eds.) Contemporary Issues in Nepalese Linguistics. 267-284. Kathmandu: Linguistic Society of Nepal.

Turin, Mark. 2004. Newar-Thangmi lexical Correspondences and the Linguistic Classification of Thangmi. Journal of Asian and African Studies. 68. 97-120.

Turin, Mark. 1998. The Thangmi Verbal Agreement System and the Kiranti Connection. Bulletin of the School of Oriental and African Studies. 61(3). 476-491. 